\title{
ANALISIS SIMULASI PENGARUH RATIO OVERLAP SUDU TERHADAP UNJUK KERJA SAVONIUS HORIZONTAL AXIS WATER TURBINE
}

\author{
Hasnul Khuluqi ${ }^{1}$, Syamsul Hadi ${ }^{1}$, Dominicus Danardono ${ }^{1}$ \\ ${ }^{1}$ Teknik Mesin - Universitas Sebelas Maret \\ e-mail addresses : khuluqi_hasnul@yahoo.com (Hasnul Khuluqi), syamsulh_st@yahoo.com (Syamsul \\ H.)Danar1405@gmail.com(D.Danardono),
}

\section{Keywords :}

Overlap Ratio ,Simulasi,

Savonius Turbine, Aspect ratio, Endplate, Torque.

\begin{abstract}
:
The rainwater which is harvested and flowed in a 3 inchdiameter pipe has potential energy that can be used to generate the turbine generator for producing electricity. This paper was focused on horizontal axis savonius turbine with varied blade overlap ratio in picohydro generator. Savonius turbine is known to utilize the drag force and work efficiently at low velocity. The purpose of this research is to find out optimal torque of savonius water turbine, and flow distribution. The results showed that the flow rate of 11.9 $l / s$ with the overlap variation of 0.3 obtained the maximum torque value of 5,22 $\mathrm{Nm}$.
\end{abstract}

\section{PENDAHULUAN}

Drag-type dan Lift-type Turbine sudah banyak dikaji oleh beberapa peneliti turbin. Penelitian Vertical Axis Water Turbine (VAWT) yang diaplikasikan untuk menggerakkan Power Generation untuk aliran air dalam pipa telah dilakukan. Perbandingan antara Drag-type Turbine dan Lift-type Turbine yang diaplikasikan pada sebuah (VAWT) telah dilakukan simulasi menggunakan CFD software maupun dengan eksperimen. Hasilnya menunjukkan Drag-type Turbine lebih baik dari pada Lift-type Turbine [1].

Pengaplikasian turbin Savonius maupun turbin Darieus dalam media air menjadi hal yang baru dalam perkembangan turbin air [1]. Hasil penelitian turbin Savonius yang diaplikasikan ke dalam air mampu menghasilkan efisiensi yang lebih besar dibandingkan dengan turbin Savonius pada media angin [2]. Momentum air yang lebih besar jika dibandingkan dengan angin mengakibatkan potensi daya yang dihasilkan oleh air jauh lebih besar. Selain itu, pemakaian turbin Savonius pada Vertical Axis Water Turbine diteliti untuk melihat pengaruh variasi rasio overlap sudu [3].

Tujuan dari penelitian ini adalah untuk mengetahui distribusi aliran fluida, dan mengetahui pengaruh rasio overlap sudu terhadap torsinya.

\section{METODOLOGI PENELITIAN}

Turbin yang diuji mempunyai dimensi yang mengacu pada jurnal yang telah diteliti sebelumnya. Turbin mempunyai overlap ratio $\beta=\mathrm{e} / \mathrm{d}$ [3]. Lengkung sudu yang digunakan adalah semi cylinder $\left(180^{\circ}\right)$, endplate $\mathrm{Do} / \mathrm{D}=1,1$ [4], dan aspect ratio As $=\mathrm{H} / \mathrm{D}=1$ [5]. Lalu, tebal plat yang digunakan adalah $2 \mathrm{~mm}$.
Dimensi turbin yang digunakan dapat dilihat pada Gambar 1.

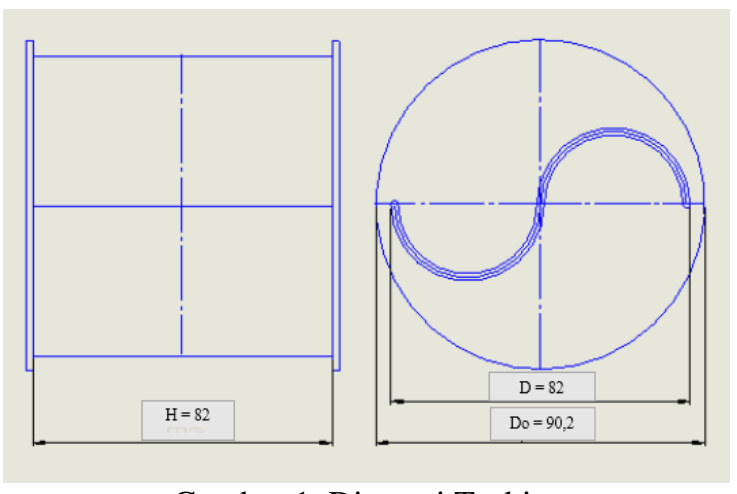

Gambar 1. Dimensi Turbin

a. Overlap Ratio

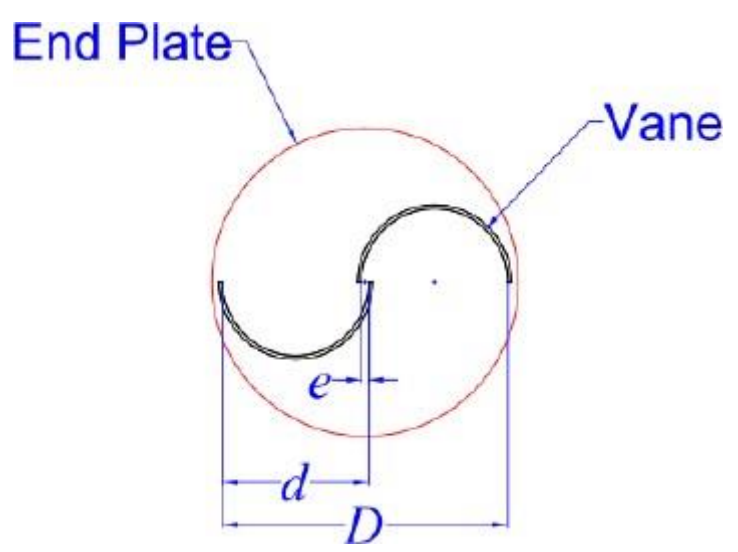

Gambar 2. Overlap ratio 


\section{b.Sampel Turbin}

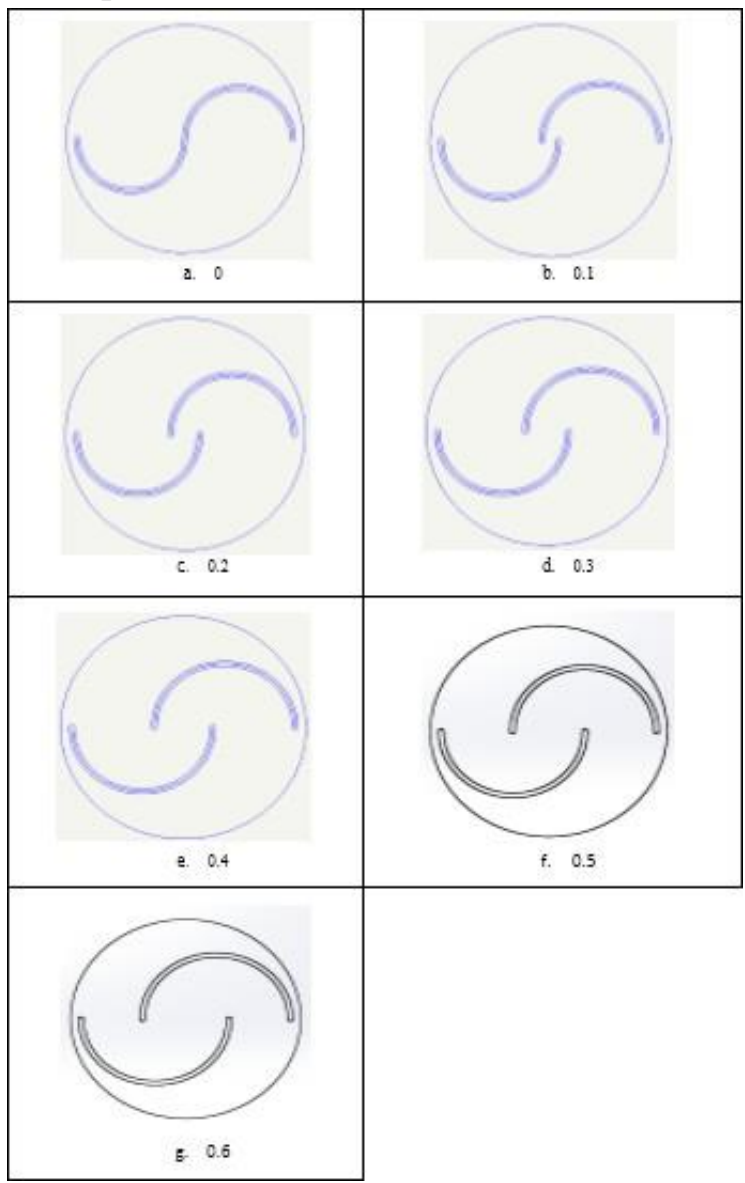

Gambar 3. Sampel Turbin

\section{c.SolidWorks}

Simulasi yang digunakan dalam penelitian ini menggunakan Computational Fluid Design (CFD) pada SolidWorks 2015. Simulasi dilakukan agar mengetahui kemungkinan desain yang terbaik. Parameter-parameter yang digunakan pada simulasi dapat dilihat pada table 1 .

Tabel 1. Parameter-parameter

\begin{tabular}{|l|l|}
\hline \multicolumn{2}{|c|}{ FLUID DOMAIN } \\
\hline Tipe Boundary & Inlet \\
\hline Mass flow rate & $11,9 \mathrm{l} / \mathrm{s}$ \\
\hline \multicolumn{2}{|c|}{ Outlet } \\
\hline Tipe Boundary & Opening \\
\hline Nilai tekanan & 1 atm \\
\hline \multicolumn{2}{|c|}{ SOLID DOMAIN } \\
\hline Material & ABS \\
\hline
\end{tabular}

\section{d. Boundary Conditions}

Simulasi yang digunakan dalam penelitian ini menggunakan Computational Fluid Design (CFD) pada SolidWorks 2015. Simulasi dilakukan sebelum pengujian dengan tujuan agar mengetahui kemungkinan desain yang terbaik. Parameter yang digunakan pada simulasi adalah debit yang mengenai sudu turbin. Debit yang digunakan adalah $11,9 \mathrm{l} / \mathrm{s}$.

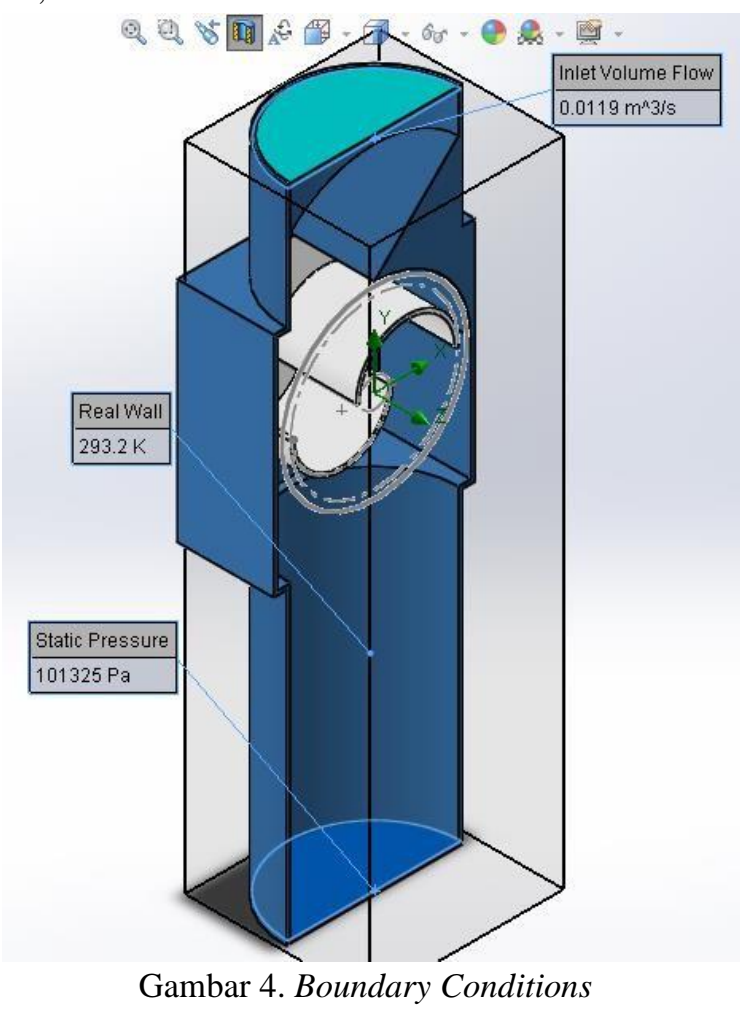

\section{HASIL DAN PEMBAHASAN}

a. Validasi Simulasi

Sebelum melaksanakan proses simulasi, satu hal yang harus diperhatikan dan dilakukan terlebih dahulu adalah melakukan validasi. Validasi dilakukan guna untuk menentukan metode yang paling tepat untuk kita gunakan dalam simulasi tersebut. Parameter yang perlu diperhatikan dalam proses validasi untuk metode simulasi ini adalah aplikasi yang digunakan dan hasil yang didapatkan. Dalam penelitian ini, simulasi akan dilakukan dengan menggunakan aplikasi Flow Simulation Solidworks, sehingga untuk menentukan validasi tersebut referensi yang digunakakan dalam penelitian sebelumnya harus dengan tema dan aplikasi yang sama. Hal tersebut harus diperhatikan guna untuk menjaga keakuratan dari hasil validasi itu sendiri.

Referensi yang digunakan dalam penelitian ini diambil dari penelitian [6]. Dalam penelitian tersebut, [6] menggunakan aplikasi Flow Simulation Solidworks guna untuk mengetahui performa turbin propeler yang telah dirancangnya. Parameter yang perlu diperhatikan dalam penelitian tersebut adalah head sebesar 1,5 $\mathrm{m}$ dan inputan berupa flow rate sebesar $1,499 \mathrm{~m}^{3} / \mathrm{s}$. Hasil yang didapatkan dalam penelitian tersebut berupa distribusi kecepatan turbin sebesar 0 hingga 10,949 m/s. 
\begin{tabular}{l|l} 
Mekanika: majalah ilmiah mekanika & 41 \\
Volume 17 Nomor 2 September 2018 &
\end{tabular}

Tabel 2. Nilai Data Validasi dan Data Percobaan

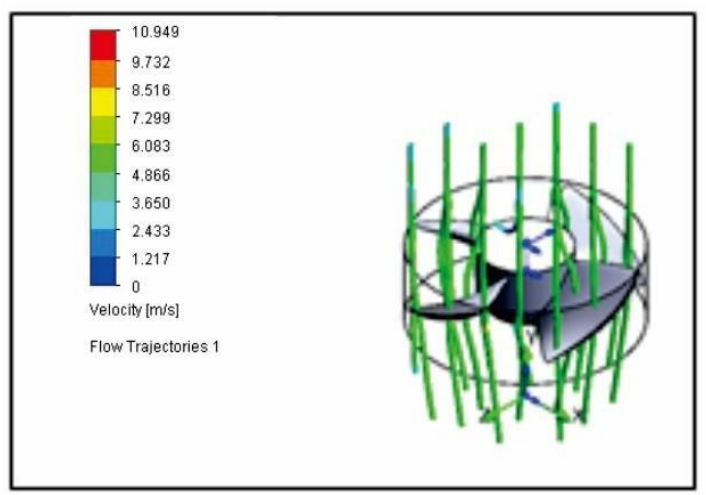

Gambar 5. Distribusi Kecepatan Turbin Propeler

Dengan mengadopsi desain turbin yang telah ada serta menggunakan parameter head dan volume flow rate yang sama, proses validasi yang dilakukan adalah dengan melakukan running ulang dengan memaksimalkan fasilitas yang terdapat dalam aplikasi Flow Simulation Solidworks tersebut. Hasil distribusi kecepatan turbin yang didapatkan adalah sebesar 0 hingga $11,220 \mathrm{~m} / \mathrm{s}$. Terdapat sedikit perbedaan antara data validasi dan data percobaan yang didapatkan. Kedua data tersebut akan dituangkan dalam gambar grafik untuk mengetahui selisih perbedaannya.

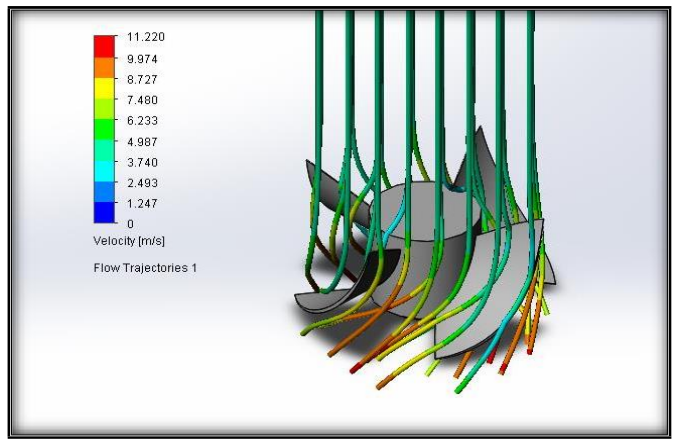

Gambar 6. Distribusi Kecepatan Turbin Propeler Hasil Simulasi Running Ulang

Perbedaan yang terjadi antara data validasi dan data percobaan terlihat relatif kecil, hal tersebut dapat dilihat dari nilai distribusi kecepatannya. Nilai data validasi (Myint) berada pada $0 \mathrm{~s} / \mathrm{d} 10,949 \mathrm{~m} / \mathrm{s}$, sementara untuk data percobaan berada pada $0 \mathrm{~s} / \mathrm{d}$ 11,220 . Setelah dikalkulasi perbedaan yang terjadi hanya sebesar $2,5 \%$, sehingga metode yang digunakan dalam simulasi menggunakan aplikasi Flow Simulation Solidworks sudah cukup valid [7].

\begin{tabular}{c|c|c|}
\hline No. & $\begin{array}{c}\text { Data } \\
\text { Validasi } \\
(\mathbf{m} / \mathbf{s})\end{array}$ & $\begin{array}{c}\text { Data } \\
\text { Percobaan } \\
\text { Simulasi } \\
(\mathbf{m} / \mathbf{s})\end{array}$ \\
\hline $\mathbf{1}$ & 0 & 0 \\
$\mathbf{2}$ & 1,217 & 1,247 \\
$\mathbf{3}$ & 2,433 & 2,493 \\
$\mathbf{4}$ & 3,690 & 3,740 \\
$\mathbf{5}$ & 4,866 & 4,987 \\
$\mathbf{6}$ & 6,347 & 6,233 \\
$\mathbf{7}$ & 7,399 & 7,480 \\
$\mathbf{8}$ & 8,516 & 8,727 \\
$\mathbf{9}$ & 9,732 & 9,974 \\
$\mathbf{1 0}$ & 10,949 & 11,220 \\
\hline
\end{tabular}

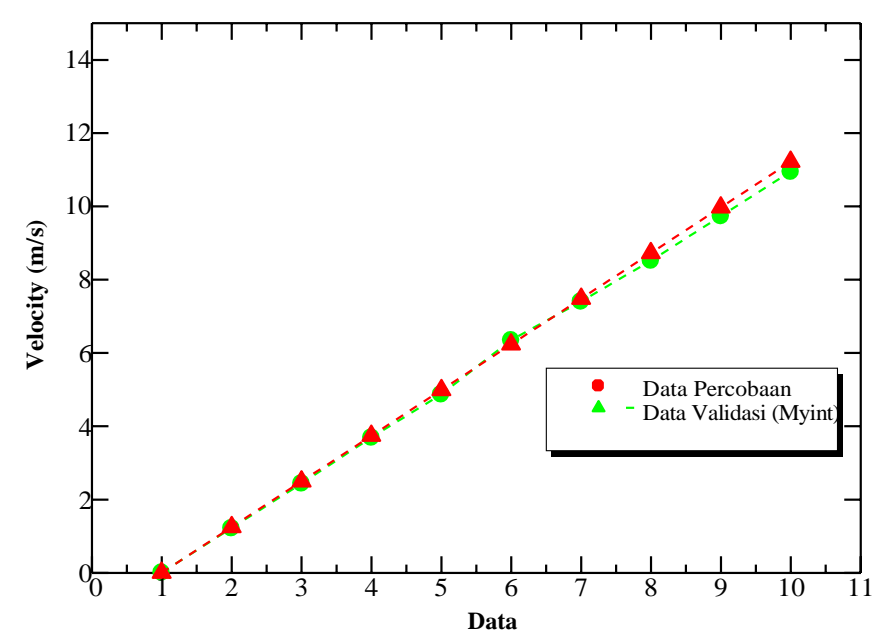

Gambar 7. Grafik Data Validasi dan Data Percobaan [7].

\section{b.Simulasi}

Setelah desain turbin selesai tahapan selanjutnya adalah pengujian secara studi simulasi dengan menggunakan Computational Fluid Design (CFD) pada SolidWorks 2015. Dengan tujuan untuk mengetahui kemungkinan desain yang terbaik dengan variasi rasio overlap sudu $0,0,1,0,2,0,3,0,4$, 0,5 , dan 0,6 . Parameter yang digunakan pada simulasi adalah debit yang mengenai sudu turbin yaitu 11, 9 l/s. Berdasarkan hasil simulasi yang diperoleh, kemudian dibuat grafik perbandingan antara rasio overlap sudu dengan torsi yang dihasilkan. Hasil nilai torsi pada masing-masing rasio overlap sudu dapat dilihat pada tabel 3 dan gambar grafik 8 . 
Tabel 3. Pengaruh Rasio Overlap terhadap Torsi.
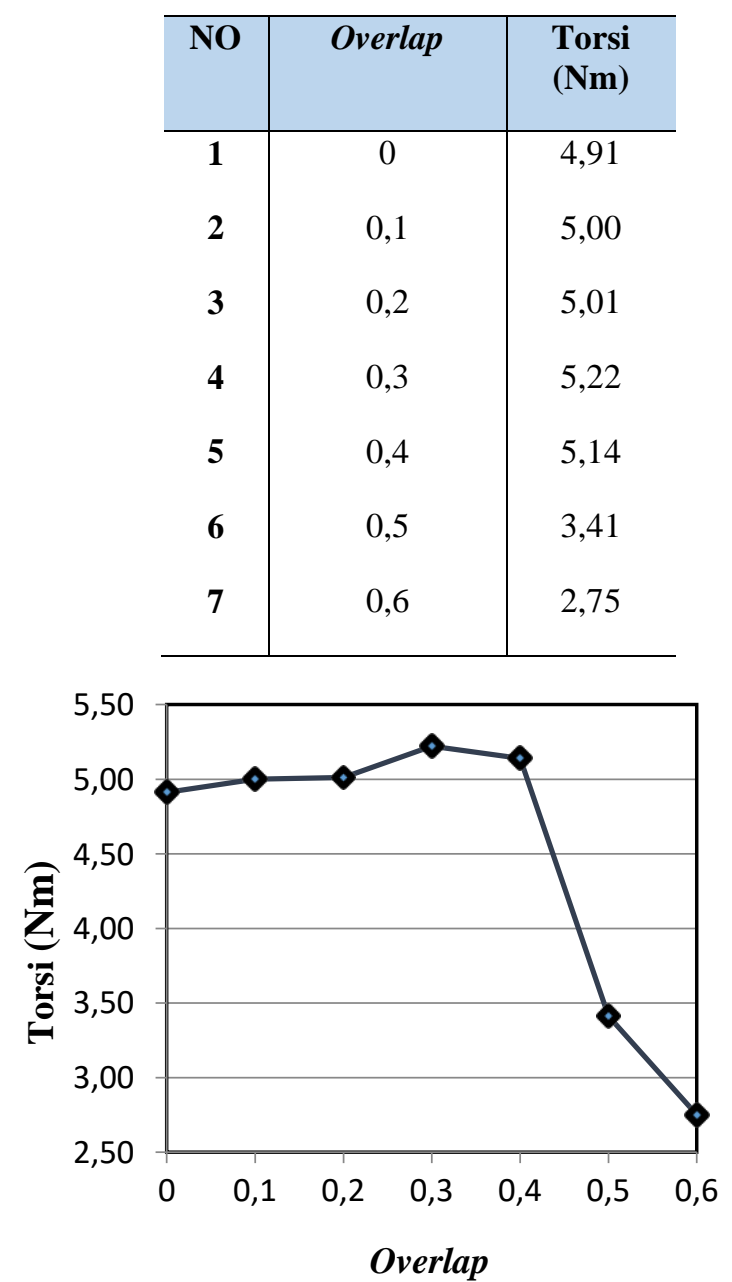

Gambar 8. Grafik pengaruh overlap ratio sudu terhadap torsi.

Gambar 8 menunjukkan nilai torsi yang terbaik terjadi pada overlap 0,3 dengan nilai torsi $5,22 \mathrm{Nm}$ dikarenakan distribusi aliran fluida pada overlap 0,3 sangat baik, pada sudu yang berlawanan arah distribusi alirannya merata mengenai sudu tersebut sehingga sudu yang berlawanan mendapatkan gaya dorong dan menghasilkan torsi yang besar. Lalu pada overlap 0,4 mengalami penurunan nilai torsi dengan torsi 5,14 Nm yang nilainya tidak terlampau jauh dari overlap 0,3 hal ini dikarenakan sudu yang berlawanan arah menghalangi laju aliran sehingga distribusi aliran terganggu yang menyebabkan nilai torsi berkurang. Pada overlap 0,2 dengan nilai torsi $5,01 \mathrm{Nm}$ mengalami penurunan nilai torsi dikarenakan celah di antara kedua sudu terlalu kecil sehingga sudu yang berlawanan arah tidak mendistribusi aliran fluida dengan baik. Overlap 0,1 dengan nilai torsi $5,00 \mathrm{Nm}$ mengalami penurunan nilai torsi dikarenakan celah di antara kedua sudu sangat kecil sehingga sudu yang berlawanan arah tidak mendistribusi aliran fluida dengan baik. Kemudian pada overlap 0 dengan nilai torsi 4,91 $\mathrm{Nm}$, nilai torsinya lebih kecil dari overlap 0,1 dikarenakan tidak adanya celah di antara kedua sudu sehingga tidak ada gaya dorong bantuan dari sudu yang berlawanan yang mengakibatkan nilai torsi pada overlap 0 lebih kecil dari overlap 0,1 . Selain itu bersarnya torsi pada overlap 0 dipengaruhi oleh faktor arah fluida yang setelah menumbuk sudu cekung berbalik arah menghambat putaran turbin. Lalu nilai torsi yang paling rendah adalah overlap 0,5 , dan 0,6 dengan nilai 3,41 $\mathrm{Nm}$ dan $2,75 \mathrm{Nm}$, hal ini dikarenakan sudu yang berlawanan arah menghalangi laju aliran fluida sehingga sudu yang tegak lurus terhadap aliran fluida menggalami penurunan gaya dorong atau gaya hambat, hal ini yang mengakibatkan nilai torsi menjadi turun. Hasil distribusi aliran pada masing-masing rasio overlap sudu dapat dilihat pada gambar 9.

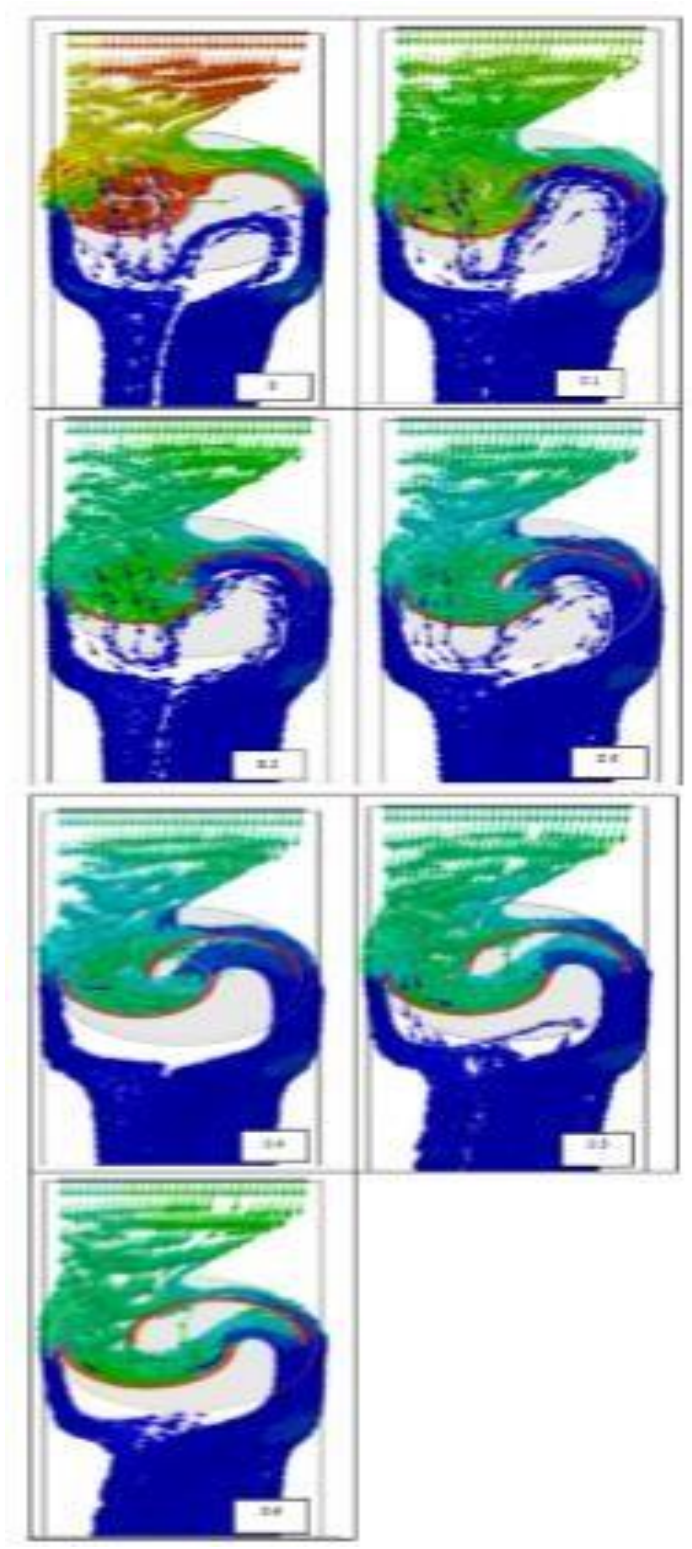

Gambar 9. Distribusi Aliran 


\section{KESIMPULAN}

Hasil data torsi dan distribusi aliran fluida menyatakan pada variasi overlap ratio 0,3 yang paling baik dengan nilai torsi sebesar 5,22 Nm.

\section{ACKNOWLEDGEMENT}

Penelitian ini didanai oleh Dana Hibah Penilitian PUPT (Penelitian Unggulan Perguruan Tinggi) Universitas Sebelas Maret, Surakarta

\section{DAFTAR NOTASI}

\begin{tabular}{|c|c|}
\hline Do & $=$ Diameter Endplate \\
\hline $\mathrm{e}$ & $=$ Celah Sudu \\
\hline $\mathrm{D}$ & $=$ Diameter sudu \\
\hline $\mathrm{d}$ & $=$ Jari-jari sudu \\
\hline $\mathrm{H}$ & $=$ Tinggi sudu \\
\hline g & $=$ Percepatan gravitasi \\
\hline Q & $=$ Debit \\
\hline $\mathrm{T}$ & $=$ Torque \\
\hline
\end{tabular}

\section{DAFTAR PUSTAKA}

[1] Chen J, dkk. "A novel vertical axis water turbine for power generation from water pipelines," Energy, vol. 54, pp. 184-193, 2013

[2] Biswas, dkk. "Experimental and computational evaluation of Savonius hydrokinetic turbine for low velocity condition with comparison to Savonius wind turbine at the same input power," Energy Conversion and Management, vol. 83, pp. 88-98, 2014.

[3] Patel, dkk. "Investigation Of Overlap Ratio For Savonius Type Vertical Axis Hydro Turbine," IJSCE ISSN: 2231-2307, vol.3, May 2013.

[4] Wenehenubun F, dkk."An experimental study on the performance of savonius wind turbine related with the number of blades", 2nd International Conference on Sustainable Energy Engineering and Application. Vol. 68, pp. 297-304, (ICSEEA-2014).

[5] M. H. Ali, "Experimental Comparation Study for Savonius Wind Turbine Of two \& Three Blades At low Wind Speed," Int. J. Of Modern Eng. Research (IJMER), vol. 3, Issue. 5, Sep - Oct. 2013 pp - $2978-2986$ ISSN : $2249-6645,2013$.

[6] Myint Y W, Win H H., "Design and Flow Simulation of Runner Blade for Propeller Turbine," ISSN 2319-8885, vol. 03,Issue.11 June-2014, pp. 2559-2562, 2014.
[7] Prasetyo H, dkk., "Simulasi Turbin Air Poros Horizontal Axis Water Turbine Dengan Menggunakan Aplikasi Flow Simulation SolidWorks." JURNAL MEKANIKA UNS, Volume-, No. 2, 2016. 